\title{
Efficacy of Nasobiliary Tubes and Biliary Stents in Management of Patients with Bile Leak after Liver Transplantation: A Systematic Review
}

\author{
Ali Raza, ${ }^{1,2}$, Anam Omer ${ }^{3}$, Sara Iqbal ${ }^{3}$, Vineet Gudsoorkar ${ }^{1}$, Pramoda Koduru ${ }^{1}$ and Kumar Krishnan ${ }^{4}$ \\ ${ }^{1}$ Division of Gastroenterology, Department of Medicine, Houston Methodist Hospital, Weill Cornell Medicine, Houston, TX, ${ }^{2}$ Division of \\ Gastroenterology, Department of Medicine, The University of Texas-Houston, McGovern Medical School, Houston, TX, ${ }^{3}$ Department of \\ Medicine, Houston Methodist Hospital, Weill Cornell Medicine, Houston, TX, ${ }^{4}$ Division of Gastroenterology, Department of Medicine, Harvard \\ Medical School, Massachusetts General Hospital, Boston, MA, USA
}

Background/Aims: Bile leak is one of the most common complications of liver transplantation. The treatment options for bile leaks include conservative management, surgical re-intervention, percutaneous drainage and endoscopic drainage. We aimed to perform a systematic review to identify the efficacy of endoscopic treatment in the resolution of post-transplant bile leaks.

Methods: Two independent reviewers performed systematic literature search in PubMed, ISI Web of Science, grey literature and relevant references in May 2017. Human studies in English with documented post-liver transplant bile leaks were included.

Results: Thirty-four studies were included in the final analysis. The pooled efficacy of biliary stents for the resolution of post-transplant bile leaks was $82.43 \%$ compared with $87.15 \%$ efficacy of nasobiliary tubes. The efficacy of biliary stents was lower for anastomotic leaks (69.23\%) compared to T-tube (90.9\%) or cut-surface/ cystic duct stump related leaks (92.8\%). Similarly, the efficacy of nasobiliary tube was also lower for anastomotic leaks (58.33\%) compared to T-tube or cut-surface related leaks (100\%).

Conclusions: In this systematic review, the overall efficacy was $82.43 \%$ in biliary stent group, and $87.15 \%$ in nasobiliary tube group. Both biliary stent and nasobiliary tube were more effective in managing non-anastomotic leaks compared to anastomotic leaks.

Clin Endosc 2019;52:159-167

Key Words: Biliary fistula; Living donor liver transplant; Deceased donor liver transplant; Nasobiliary tube; Biliary stent

\section{INTRODUCTION}

Liver transplantation (LT) is the only treatment available for end-stage liver disease. Roughly 25,000 annual LTs are performed worldwide, and 6,000 of those are performed in the US. ${ }^{1}$ Biliary complications, mainly bile leaks (BLs) and stric-

Received: July 3, 2018 Revised: October 5, 2018

Accepted: October 6, 2018

Correspondence: Ali Raza

Division of Gastroenterology, Department of Medicine, The University of Texas-Houston, McGovern Medical School, 7000 Fannin Street, Houston, TX 77030, USA

Tel: +1-313-685-0050, Fax: +1-713-500-6699, E-mail: Ali.Raza@uth.tmc.edu ORCID: https://orcid.org/0000-0001-6939-1079

(c) This is an Open Access article distributed under the terms of the Creative Commons Attribution Non-Commercial License (http://creativecommons.org/ licenses/by-nc/3.0) which permits unrestricted non-commercial use, distribution, and reproduction in any medium, provided the original work is properly cited. tures are observed in $8 \%-19 \%$ of $\mathrm{LT}^{2}$. The incidence has been decreasing given improvements in surgical techniques for biliary reconstruction, patient selection and improved immunosuppression. A recent systematic review reported the overall rate of BLs was $8.2 \%{ }^{3}$ In this review, the onset of $\mathrm{BL}$ ranged from post-operative day 1 to 6-months, and the incidence in deceased donor liver transplant (DDLT) and living donor liver transplant (LDLT) was $7.8 \%$ and $9.5 \%$, respectively. In the earlier transplant experience, BLs were managed surgically, which resulted in significant morbidity and mortality. ${ }^{4}$ As a result, minimally invasive approaches have been favored.

Endoscopic retrograde cholangiography (ERC) is the most common primary treatment approach for post-transplant BLs. There is significant evidence regarding the safety and efficacy of ERC in the management of post-transplant BLs in the last three decades, and it has become the standard care 
for management of such patients. ${ }^{5-7}$ The primary endoscopic treatment strategy includes the placement of a trans-papillary biliary endoprosthesis that diverts the flow of bile preferentially into the duodenum, or externally. The endoprosthesis that have been used include plastic stents and nasobiliary tubes (NBTs).

Here, we reviewed the literature regarding the clinical efficacy of biliary stents (BS) and NBT placement for the treatment of post-transplant BL. The primary goal of the systematic review was to identify the overall efficacy (assessed by resolution of BL) of BS and NBT in post-transplant BLs. Secondary outcomes included healing time for the BL, adverse events associated BS and NBT and duration BS and NBT insertion. We further sought to assess the need for any additional ERCs, surgical re-interventions or interventional radiology procedures needed to treat BL.

\section{MATERIALS AND METHODS}

\section{Study selection}

We selected studies that included patients undergoing LT for various indications and developed BL post-operatively. Studies including patients who underwent BS or NBT placement for the management of $\mathrm{BL}$ in adult and pediatric population were reviewed. We included controlled trials, pro- spective or retrospective cohort studies and case series. We excluded studies that (a) included patients with post-operative $\mathrm{BL}$ from surgeries other than liver transplant (b) case reports and (c) did not have a follow-up duration for the assessment of BL. In a case of duplicate or overlapping studies, most recent publication was used for inclusion and analysis.

\section{Search strategy}

A systematic search was performed in multiple electronic databases (PubMed; ISI Web of Science), grey literature and review of pertinent references of included studies by three independent researchers (AR, AO and VG) in November 2016. Human studies in English published from 1991-2016 were screened. Boolean search was conducted using the terms "Liver transplant AND bile leak". Mesh terminology used for the search was: "Liver Transplantation"[Mesh] AND "Bile"[Mesh] AND leak [All Fields]. Handsearching of the relevant evidence was also performed to ensure inclusiveness. Final exploration of the electronic databases was performed on May 26th, 2017 and the search results were updated (Fig. 1). Two additional researchers evaluated the titles and abstracts of initially screened studies to assess inclusion (SI and PK). Full texts of the eligible articles were then carefully examined to determine inclusion for qualitative analysis. Any inconsistencies among reviewers were resolved by consensus or discussion with a

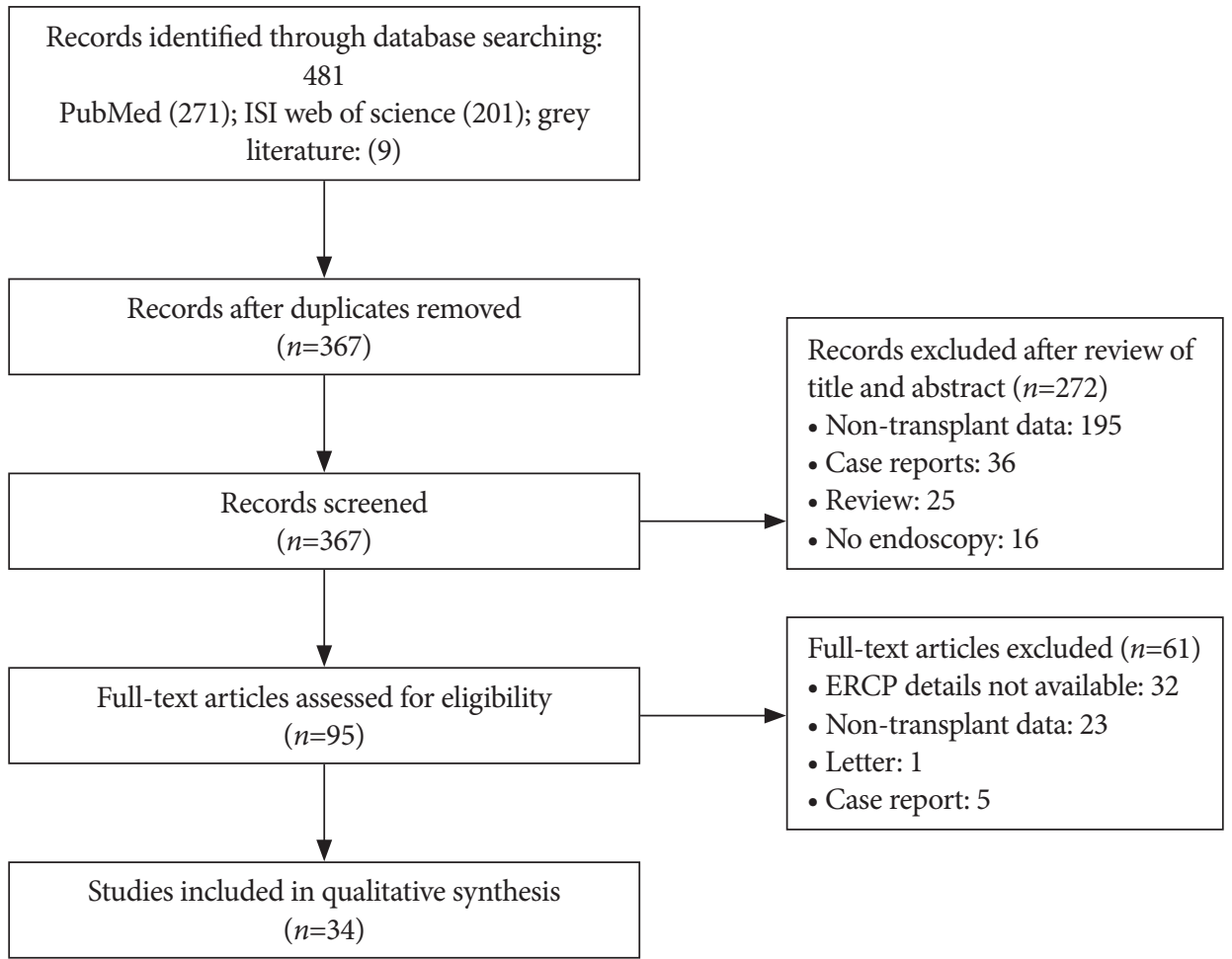

Fig. 1. PRISMA flow diagram. ERCP, endoscopic retrograde cholangiopancreatography. 
third reviewer (KK). One reviewer (AR) contacted the authors, if needed, for additional information.

\section{Data abstraction and definitions}

A standardized form was used by three independent reviewers (AR, $\mathrm{AO}$ and $\mathrm{VG}$ ) who extracted the following data from relevant studies: author, study name, type of study (retrospective or prospective), peer reviewed full publication or abstract, number of patients undergoing biliary stenting, or receiving NBT, demographic information of the patients, living donor or cadaveric transplant, type of biliary anastomosis (hepaticojejunostomy or duct to duct anastomosis), onset/ recognition of $\mathrm{BL}$, site of $\mathrm{BL}$, adverse reaction from placement of BS or NBT, duration of BS or NBT insertion, need for further intervention for persistent BL (endoscopic, surgical or radiological). Any discrepancy was resolved with consensus or input from a third reviewer (KK). BL was suspected when a transplant recipient developed clinical symptoms (Abdominal pain, jaundice, fever etc.) or abnormal liver function tests. BL was confirmed based on the imaging (direct cholangiography via T-tube or NBT, hepatobiliary scintigraphy), ERC or bilious intra-abdominal drain out-put.

\section{Quality assessment}

Using the Newcastle-Ottawa quality assessment scale (NOQAS) for the cohort studies, we assessed the quality of included studies. We also included following ad hoc quality criteria: (i) total number of patients more than 10 and (ii) peer reviewed full publication.

\section{Outcomes assessment}

Primary outcome: Primary outcome was to assess the overall efficacy of BS or NBT in resolution of post-transplant BL in the recipients.

Secondary outcomes: Secondary outcomes included: (a) time to resolution of BL after NBT or BS insertion, (b) duration of prosthesis (BS, NBT) in patients with BL, (c) need for further interventions (endoscopic, radiologic or surgical) in patients who failed to heal the BL after BS or NBT placement and (d) complications arising from endoscopic BS or NBT insertion

\section{RESULTS}

A systematic search of data was performed in November 2

016, and the search was updated on May 26th, 2017. After removal of duplicates, 367 studies were identified by literature search. Review of title and abstract excluded 272 studies. Another 61 studies were excluded after full text review (reasons mentioned in the Fig. 1).

Thirty-four studies ( 29 retrospective, 5 prospective) were included in the final analysis. ${ }^{2,4,8-39}$ Thirty- three studies were peer-reviewed full publications and medium quality as assessed by NOQAS, while one study ${ }^{15}$ was a published research abstract and was low quality. Sixteen studies involved more than 10 patients. Two studies reported outcomes in both DDLT and LDLT, ${ }^{13,32}$ six in DDLT, ${ }^{4,11,19,21,30,39}$ four in LDLT $^{18,20,34,36}$ and twenty-two studies did not specify the type of transplant. A total of 370 post-transplant patients with confirmed BLs (anastomotic leak: 179, T-tube: 84, cut surface/ duct of Luschka/cystic duct/others: 25 , not reported: 82 ) treated with BS and a total of 179 post-transplant patients with confirmed BLs (anastomotic leak: 36, T-tube: 78, cut surface/ duct of Luschka/cystic duct/others: 11, not reported: 54) treated with NBT, were reviewed.

Details of study design and characteristics are listed in Tables 1, 2 for BS; and Tables 3, 4 for BLs treated with NBTs.

\section{Biliary stents Efficacy of BS}

A total of 370 patients with confirmed post-transplant BLs who were treated with BS were identified. The pooled efficacy for the resolution of post-transplant BLs treated with BS was 82.43\% (278/370). Among patients who had documented leak related to the choledochocholedochostomy, the efficacy of BS was $69.23 \%$ (90/130), the remaining 49 patients with anastomotic leaks did not have outcome mentioned in their subgroup analysis. Efficacy of BS among patients with documented T-tube related BL was 90.9\% (68/74; remaining 10 patients with T-tube related leak did not have outcome mentioned in their sub-group analysis). Similarly, efficacy of BS for other causes of BL (cut surface, duct of Luschka and cystic duct stump) was also $92.8 \%$ (13/14, remaining 11 patients did not documented outcome of stenting in the sub-group analysis). The site of BL was not mentioned in the rest of the patients ( 82 patients). In cases where the type of transplant was specifically mentioned, BS was effective in controlling the BL in $93.7 \%$ (30/32) of LDLT and 76.47\% (52/68) of DDLT patients.

When 14 studies with low quality and less number of patients (less than 10) were excluded, the pooled efficacy of BS for the resolution of BL was $77.6 \%$ (204/263). Sub-group analyses for BS efficacy in 11 medium quality studies with more than 10 patients showed: $64.7 \%$ (66/102) in duct-to-duct anastomosis, 90.5\% (57/63) in T-tube related leak, 90.9\% (10/11) in other causes (cystic duct stump, duct of Luschka etc.) of leak, 91.7\% (22/24) in LDLT and 76.2\% (48/63) in DDLT.

\section{Efficacy of covered self-expandable metal stents}

Four studies reported data on covered self-expandable met- 
Table 1. Design of the Studies Using Biliary Stents for Management of Bile Leak

\begin{tabular}{|c|c|c|c|c|}
\hline Study & Study population \& country of origin & Study design & Control group & $\begin{array}{c}\text { Study quality } \\
\text { (NOQAS) }\end{array}$ \\
\hline Sherman et al. $(1993)^{4}$ & US; adult & Prospective & Historical & Medium \\
\hline Tung et al. (1999) & US; adult & Retrospective & None & Medium \\
\hline Saab et al. $(2000)^{25}$ & US; no age-group mentioned & Retrospective & Historical & Medium \\
\hline Pfau et al. $(2000)^{23}$ & US; adult & Retrospective & None & Medium \\
\hline Morelli et al. $(2001)^{10}$ & US; adult & Retrospective & None & Medium \\
\hline Rerknimitr et al. $(2002)^{24}$ & US; adult and pediatric & Retrospective & Historical & Medium \\
\hline Thuluvath et al. $(2003)^{2}$ & US; adult and pediatric & Retrospective & None & Medium \\
\hline Park et al. $(2003)^{12}$ & Korea; adult & Retrospective & None & Medium \\
\hline Khuroo et al. $(2005)^{8}$ & Saudi Arabia; adult and Pediatric & Retrospective & None & Medium \\
\hline Johnston et al. $(2006)^{11}$ & US; adult and pediatric & Retrospective & None & Medium \\
\hline Pacholczyk et al. $(2006)^{13}$ & Poland; no age-group mentioned & Retrospective & None & Medium \\
\hline Liao et al. $(2007)^{14}$ & China; adult & Prospective & Historical & Medium \\
\hline Solmi et al. $(2007)^{17}$ & Italy; adult & Retrospective & None & Medium \\
\hline Tarantino et al. $(2008)^{27}$ & Italy; adult & Prospective & None & Medium \\
\hline Lee et al. $(2008)^{9}$ & Taiwan; adult & Retrospective & None & Medium \\
\hline Traina et al. $(2009)^{28}$ & Italy; adult & Retrospective & None & Medium \\
\hline Phillips et al. $(2011)^{19}$ & US; adult & Retrospective & None & Medium \\
\hline Papachristou et al. $(2011)^{21}$ & US; adult and pediatric & Prospective & None & Medium \\
\hline Gunawansa et al. $(2011)^{22}$ & Sri Lanka; adult and pediatric & Prospective & None & Medium \\
\hline Sanna et al. $(2011)^{26}$ & Italy, adult & Retrospective & None & Medium \\
\hline Martins et al. $(2012)^{30}$ & US; adult & Retrospective & None & Medium \\
\hline Sendino et al. $(2018)^{15}$ & US; no age-group mentioned & Retrospective & None & Low \\
\hline Leiting et al. $(2016)^{18}$ & US; adult & Retrospective & None & Medium \\
\hline Chok et al. $(2016)^{20}$ & Hong Kong; no age-group mentioned & Retrospective & None & Medium \\
\hline DaVee et al. $(2017)^{29}$ & US; adult & Retrospective & None & Medium \\
\hline
\end{tabular}

NOQAS, Newcastle-Ottawa quality assessment scale.

al stents (CSEMS) ${ }^{19,28-30}$ Three studies ${ }^{19,28,29}$ described outcomes in fully covered self-expandable metal stents (FCSEMS) while one study ${ }^{30}$ reported outcomes for both FCSEMS and partially covered self-expandable metal stents (PCSEMS). Two studies exclusively included patients who failed previously placed plastic stents, ${ }^{28,29}$ and the other two studies reported patients with endoscopic treatment failure (previous plastic stents) as well as treatment naïve patients. ${ }^{19,30}$ Overall efficacy CSEMS for resolution of BL was 87.5\% (49/56). Efficacy of CSEMS for treatment naïve and refractory BL was 93.75\% (15/16) and $86.7 \%(13 / 15)$ respectively, while refractoriness of BL was not mentioned in the remaining 25 patients. Efficacy of FCSEMS and PCSEMS for resolution of BL was $86.8 \%(46 / 53)$ and $100 \%(3 / 3)$ respectively. Frequency of complications from CSEMS included: 18 (32\%) biliary strictures after the stent removal ( 2 patients managed with surgeries; 12 with repeat plastic or metal stents; 2 conservatively and no treatment mentioned in 2 patients); 6 biliary pathologies like ulcerations, inflammation or hyperplasia at stent site; one cholangitis and one stent migration.

\section{Onset of BL and duration of BS placement}

The pooled mean onset of BL in the studies reporting "mean onset" was 46.4 days (range, 1-184 days) after transplant. Two studies reported the median onset of BLs (17 and 21 days), and two studies provided range for the onset of BL (2-days-4months; 2-weeks-2-years). The BS was kept in place for as long as it was deemed necessary to heal the BL. If BL was refractory to repeated stenting, patients further underwent surgery or radiological intervention. Two studies reported median duration for which stents stayed in biliary tree (37 days, 150 days), another two studies reported the range (6-8 
Table 2. Characteristics of the Studies Using Biliary Stents for Management of Bile Leaks

\begin{tabular}{|c|c|c|c|c|c|}
\hline Study & $\begin{array}{l}\text { Number of } \\
\text { patients }\end{array}$ & $\begin{array}{l}\text { LD, DD trans- } \\
\text { plant }\end{array}$ & $\begin{array}{c}\text { Onset of bile leak } \\
\text { (days) }\end{array}$ & $\begin{array}{l}\text { Site of bile leak (anasto- } \\
\text { motic, T-tube, others) }\end{array}$ & $\begin{array}{l}\text { Resolution of bile } \\
\text { leak (no. of patients) }\end{array}$ \\
\hline Sherman et al. $(1993)^{4}$ & 5 & No mention & No mention & Anastomotic: 5 & $4(80 \%)$ \\
\hline Tung et al. $(1999)^{16}$ & 2 & No mention & 45 (mean) & $\begin{array}{l}\text { Anastomotic: } 1 \\
\text { T-tube: } 1\end{array}$ & $2(100 \%)$ \\
\hline Saab et al. $(2000)^{25}$ & 21 & No mention & 124 (mean) & T-tube: 21 & $15(71 \%)$ \\
\hline Pfau et al. $(2000)^{23}$ & 30 & No mention & $14-730$ (range) & $\begin{array}{l}\text { Anastomotic: } 7 \\
\text { T-tube: } 21 \\
\text { Others: } 2\end{array}$ & $26(23 \%)$ \\
\hline Morelli et al. $(2001)^{10}$ & 25 & No mention & 66.8 (mean) & $\begin{array}{l}\text { Anastomotic: } 10 \\
\text { T-tube: } 11 \\
\text { Others: } 4\end{array}$ & $24(96 \%)$ \\
\hline Rerknimitr et al. $(2002)^{24}$ & 14 & No mention & 65 (mean) & $\begin{array}{l}\text { Anastomotic: } 7 \\
\text { T-tube: } 6 \\
\text { Others: } 1\end{array}$ & $14(100 \%)$ \\
\hline Thuluvath et al. $(2003)^{2}$ & 19 & No mention & No mention & $\begin{array}{l}\text { Anastomotic: } 5 \\
\text { T-tube: } 10 \\
\text { Others: } 1 \\
\text { Location not identified: } 3\end{array}$ & $16(84 \%)$ \\
\hline Park et al. $(2003)^{12}$ & 3 & No mention & 21 (median) & No mention & $3(100 \%)$ \\
\hline Khuroo et al. $(2005)^{8}$ & 2 & No mention & No mention & Anastomotic: 2 & $2(100 \%)$ \\
\hline Johnston et al. $(2006)^{11}$ & 15 & DD: 15 & 49 (mean) & $\begin{array}{l}\text { Anastomotic: } 2 \\
\text { T-tube: } 13\end{array}$ & $13(87 \%)$ \\
\hline Pacholczyk et al. $(2006)^{13}$ & 4 & $\begin{array}{l}\text { LD: } 2 \\
\text { DD: } 2\end{array}$ & No mention & $\begin{array}{l}\text { T-tube: } 3 \\
\text { Others: } 1\end{array}$ & $4(100 \%)$ \\
\hline Liao et al. $(2007)^{14}$ & 6 & No mention & $2-120$ days (range) & No mention & $3(50 \%)$ \\
\hline Solmi et al. $(2007)^{17}$ & 7 & No mention & No mention & No mention & $6(86 \%)$ \\
\hline Tarantino et al. $(2008)^{27}$ & 26 & No mention & No mention & Anastomotic: 26 & $6(23 \%)$ \\
\hline Lee et al. $(2008)^{9}$ & 7 & No mention & No mention & No mention & $7(100 \%)$ \\
\hline Traina et al. $(2009)^{28}$ & 5 & No mention & No mention & Anastomotic: 5 & $5(100 \%)$ \\
\hline Phillips et al. $(2011)^{19}$ & 17 & DD: 17 & 18 (median) & $\begin{array}{l}\text { Anastomotic: } 14 \\
\text { Others: } 3\end{array}$ & $16(94 \%)$ \\
\hline Papachristou et al. $(2011)^{21}$ & 3 & DD: 3 & No mention & T-tube: 3 & $0(0 \%)$ \\
\hline Gunawansa et al. $(2011)^{22}$ & 8 & No mention & 17 (median) & $\begin{array}{l}\text { Anastomotic: } 6 \\
\text { T-tube: } 2\end{array}$ & $8(100 \%)$ \\
\hline Sanna et al. $(2011)^{26}$ & 7 & No mention & No mention & T-tube: 7 & $7(100 \%)$ \\
\hline Martins et al. $(2012)^{30}$ & 31 & DD: 31 & 37.4 (mean) & $\begin{array}{l}\text { Anastomotic: } 22 \\
\text { Nonanastomotic: } 9\end{array}$ & $22(71 \%)$ \\
\hline Sendino et al. $(2018)^{15}$ & 42 & No mention & No mention & No mention & $39(93 \%)$ \\
\hline Leiting et al. $(2016)^{18}$ & 24 & LD: 24 & No mention & $\begin{array}{l}\text { Anastomotic: } 22 \\
\text { Others: } 2\end{array}$ & $22(92 \%)$ \\
\hline Chok et al. $(2016)^{20}$ & 6 & LD: 6 & No mention & Anastomotic: 6 & $6(100 \%)$ \\
\hline DaVee et al. $(2017)^{29}$ & 43 & No mention & No mention & Anastomotic: 43 & $35(81 \%)$ \\
\hline
\end{tabular}

$\mathrm{DD}$, deceased donor; LD, living donor. 
Table 3. Design of the Studies Using Nasobiliary Tubes for Management of Bile Leaks

\begin{tabular}{lllcc}
\hline Study & Study population \& country of origin & Study design & Control group & $\begin{array}{c}\text { Study quality } \\
\text { (NOQAS) }\end{array}$ \\
\hline Ostroff et al. $(1990)^{38}$ & US; adult & Retrospective & None & Medium \\
\hline Osorio et al. $(1993)^{34}$ & US; adult and pediatric & Retrospective & None & Medium \\
\hline Sherman et al. $(1993)^{4}$ & US; adult & Prospective & Historical & Medium \\
\hline Sherman et al. $(1995)^{35}$ & US; adult & Retrospective & None & Medium \\
\hline Bourgeois et al. $(1995)^{39}$ & Belgium; adult & Retrospective & None & Medium \\
Macfarlane et al. $(1996)^{36}$ & UK; adult & Retrospective & None & Medium \\
\hline Saab et al. $(2000)^{25}$ & US; no mention of age group & Retrospective & Historical & Medium \\
\hline Shah et al. $(2002)^{33}$ & UK; adult & Retrospective & None & Medium \\
Rerknimitr et al. $(2002)^{24}$ & US; adult & Retrospective & None & Medium \\
Park et al. $(2003)^{12}$ & Korea; adult & Retrospective & None & Medium \\
Hwang et al. $(2006)^{37}$ & Korea; adult & Retrospective & None & Medium \\
\hline Tsujino et al. $(2006)^{31}$ & Japan; adult & Retrospective & None & Medium \\
\hline Liao et al. $(2007)^{14}$ & China; adult & Prospective & Historical & Medium \\
\hline Oh et al. $(2015)^{32}$ & Korea; adult & Retrospective & None & Medium \\
\hline
\end{tabular}

NOQAS, Newcastle-Ottawa quality assessment scale.

Table 4. Characteristics of the Studies Using Nasobiliary Tubes for Management of Bile Leaks

\begin{tabular}{|c|c|c|c|c|c|}
\hline Study & $\begin{array}{l}\text { Number of } \\
\text { patients }\end{array}$ & LD, DD transplant & $\begin{array}{c}\text { Onset of bile leak } \\
\text { (days) }\end{array}$ & $\begin{array}{l}\text { Site of bile leak (anasto- } \\
\text { motic, T-tube, others) }\end{array}$ & $\begin{array}{l}\text { Resolution of } \\
\text { bile leak }\end{array}$ \\
\hline Ostroff et al. $(1990)^{38}$ & 12 & No mention & 210 & T-tube: 12 & $12(100 \%)$ \\
\hline Osorio et al. $(1993)^{34}$ & 17 & No mention & No mention & T-tube: 17 & $17(100 \%)$ \\
\hline Sherman et al. $(1993)^{4}$ & 13 & DD: 13 & 102 (mean) & T-tube: 13 & $13(100 \%)$ \\
\hline Sherman et al. $(1995)^{35}$ & 26 & No mention & No mention & T-tube: 26 & $26(100 \%)$ \\
\hline Bourgeois et al. $(1995)^{39}$ & 5 & DD: 5 & 84 (mean) & T-tube: 5 & $5(100 \%)$ \\
\hline Macfarlane et al. (1996) ${ }^{36}$ & 2 & No mention & 72 (mean) & No mention & $0(0 \%)$ \\
\hline Saab et al. $(2000)^{25}$ & 45 & No mention & 159 (mean) & No mention & $42(93 \%)$ \\
\hline Shah et al. $(2002)^{33}$ & 3 & No mention & 30 & Anastomotic: 3 & $3(100 \%)$ \\
\hline Rerknimitr et al. $(2002)^{24}$ & 2 & No mention & No mention & No mention & $2(100 \%)$ \\
\hline Park et al. $(2003)^{12}$ & 5 & No mention & 21 (median) & No mention & $2(40 \%)$ \\
\hline Hwang et al. $(2006)^{37}$ & 4 & LD: 4 & No mention & Anastomotic: 4 & $4(100 \%)$ \\
\hline Tsujino et al. $(2006)^{31}$ & 3 & LD: 3 & No mention & Anastomotic: 2 ; others; 1 & $3(100 \%)$ \\
\hline Liao et al. $(2007)^{14}$ & 2 & No mention & $2-120$ & $\begin{array}{l}\text { Anastomotic: } 1 \\
\text { T-tube: } 1\end{array}$ & $1(50 \%)$ \\
\hline Oh et al. $(2015)^{32}$ & 41 & $\begin{array}{l}\text { LD: } 36 \\
\text { DD: } 5\end{array}$ & No mention & $\begin{array}{l}\text { Anastomotic: } 27 \\
\text { T-tube: } 4 \\
\text { Others: } 10\end{array}$ & $26(63 \%)$ \\
\hline
\end{tabular}

$\mathrm{DD}$, deceased donor; LD, living donor.

weeks, 1-8 months) and six studies mentioned the mean duration (97.8 days). In the included studies, an ERC was generally performed after 4-12 weeks of the index procedure for assessment of $\mathrm{BL}$ and stent removal/exchange.

\section{Additional interventions when BS failed}

All patients with resolution of BL after first ERC underwent a repeat procedure for stent removal. In patients without $\mathrm{BL}$ resolution at the second ERC, they either underwent multiple 
subsequent ERCs with plastic or fully covered metal stents, surgeries (13 patients needed biliary reconstruction, 7 needed re-transplant and 10 patients underwent hepaticojejunostomy) or radiologically placed percutaneous trans-hepatic biliary drainage catheter. Only few studies mentioned the number or follow-up of surgical or radiological procedures when endoscopic therapy failed.

\section{Complications of $B S$ placement}

Very few studies reported ERC-related complications that included: pancreatitis, bleeding, stent migration and stent occlusion resulting in cholangitis.

\section{Nasobiliary tubes Efficacy of NBT}

A total of 179 patients with confirmed post-transplant BLs who were treated with NBT insertion were identified. The pooled efficacy for the resolution of post-LT related leaks treated with NBT was 87.15\% (156/179). Among patients who had documented leak related to the choledochocholedochostomy, the efficacy of NBT was $58.33 \%$ (21/39). Efficacy of NBT among patients with documented T-tube related BL was $100 \%$ (78/78). Similarly, efficacy of NBT for other causes of BL (duct of Luschka and cystic duct stump) was also 100\% (11/11). The site of BL was not mentioned in the rest of the patients (51 patients).

In cases where the type of transplant was specifically mentioned, NBT was effective in controlling the BL in $67.44 \%$ (29/43) of LDLT and 100\% (22/22) of DDLT patients. All 22 patients in the DDLT group had leaks originating from the anastomosis. In the LDLT group, 34/43 patients had leaks associated with the anastomosis. In this subgroup, NBT were effective at managing post-operative leaks in 19/34 patients (55.8\%).

\section{Onset of BL and duration of NBT placement}

The pooled mean onset of BL in the studies reporting "mean onset" was 109.5 days (range, 72-159 days) after transplant. ${ }^{4,25,3,39}$ One study ${ }^{12}$ reported the median onset of BLs (21 days), and one study ${ }^{14}$ provided range for the onset of BL (2 days -4 months). The pooled mean duration the NBT stayed in place was 10.1 days in the seven studies that mentioned it, while one study mentioned the range for the duration of NBT insertion (3-14 days). The remaining studies did not mention how long an NBT stayed in place prior to its removal.

\section{Additional interventions when NBT failed}

In those patients with persistent leaks despite NBT placement (23 patients), specific treatments were mentioned in 12 patients. Five patients underwent surgical intervention for the repair of BL. Indication in these patients included persistent BL despite multiple endoscopic attempts. One patient underwent surgery due to perforation related with NBT placement. Five patients underwent endoscopic placement of plastic BSs for persistent leaks. One patient underwent percutaneous biliary drainage due to the presence of biliary stricture.

\section{Complications of NBT placement}

There were three ERC-related complications: one patient developed perforation and underwent surgery, while two patients had bleeding. There were no procedure-related deaths noted in the patients. No studies reported post-ERC pancreatitis.

\section{DISCUSSION}

We report that biliary stenting and NBT placement are both effective treatment options for the management of posttransplant BLs. In our systematic review, the overall efficacy of BS was $82.43 \%$ compared to $87.15 \%$ efficacy of NBTs. Both BS and NBT were highly efficacious for T-tube and cystic duct stump leaks, but the efficacy appears lower for anastomotic leaks (Table 5). DaVee et al. ${ }^{29}$ looked at the refractory BLs and noted that hepatic artery disease and portal vein thrombosis were significant contributing factors for the refractory leaks. Hepatic vascular compromise leads to stricturing of the bile duct, which in turns leads to the anastomotic leak. More studies looking at in-depth analysis of the other contributing factors underlying the low success rate for anastomotic BLs are needed. There are certain advantages and disadvantages of both treatment modalities. Disadvantages of NBTs include patient discomfort, easy dislodgement and extra nursing care for the management of the tube. Advantages include ability to do a cholangiogram on demand to look for evidence of healing prior to removal and no need for an additional endoscopic retrograde cholangiopancreatography (ERCP) for its removal. BS avoids the patient discomfort associated with NBT, but almost always needs repeat ERCP for the removal.

$\mathrm{BL}$ is one of the most common post-transplant biliary complications. ERC is considered the gold standard for the diagnosis of BL, and also provides opportunity for therapeutic intervention if there is any evidence of anastomotic stricture. ${ }^{40}$ The primary aim of the endoscopic prosthesis insertion is to decompress the biliary system and divert the bile flow away from the leak site. ${ }^{34}$ In this systematic review, the overall efficacy of BS for the resolution of post-transplant BLs was $82.43 \%$, the efficacy was much lower for anastomotic leaks (69.23\%) compared to T-tube related BLs (90.9\%) and other causes (92.8\%) of BL (cut surface, duct of Luschka and 
Table 5. Comparison of the Nasobiliary Tube and Biliary Stent

\begin{tabular}{|c|c|c|}
\hline & Nasobiliary tube & Biliary stent \\
\hline Advantages & $\begin{array}{l}\text { Easy to remove (no additional procedure) } \\
\text { Ability to perform on-demand cholangiogram }\end{array}$ & $\begin{array}{l}\text { No discomfort to the patient } \\
\text { No additional/extra nursing care needed }\end{array}$ \\
\hline Disadvantages & $\begin{array}{l}\text { Patient discomfort } \\
\text { Dislodges easily }\end{array}$ & Needs additional ERCP for stent removal \\
\hline \multicolumn{3}{|l|}{ Resolution of bile leak } \\
\hline Overall & $87.15 \%$ & $82.43 \%$ \\
\hline Anastomotic leak & $58.33 \%$ & $69.23 \%$ \\
\hline Non-anastomotic leak & $100 \%$ & $92.8 \%$ \\
\hline
\end{tabular}

ERCP, endoscopic retrograde cholangiopancreatography.

cystic duct stump). The overall efficacy of NBT was $87.15 \%$. The resolution of leak appears to be higher for T-Tube related leaks (100\%) and cystic duct stump/duct of Luschka leaks (100\%) compared to leaks specifically related to the anastomosis (58.33\%). We further noted a higher efficacy for NBT for resolving post-transplant BLs in patients who underwent DDLT (100\%) compared to LDLT (67.44\%). As there are no randomized controlled prospective trials comparing NBT to plastic stenting, there cannot be a direct comparative conclusion from this study regarding NBT vs. plastic stents.

Publication bias is an inherent issue of the systematic review. We only selected studies reporting outcomes in English, so language bias could also affect the results of our study. Most important limiting factor for our systematic review was that we included studies with significant heterogeneity in patient population, study design and outcomes. The included studies in this systematic review had multiple variabilities which could potentially interfere with the results and introduce bias, for example, some studies in our systematic review did not mention variables such as: site of BL, type of stent used, catheter size for the NBT, duration of follow-up, number of additional ERCs to achieve resolution of $\mathrm{BL}$, complications from ERC and management of refractory BLs.

Despite all these factors, this is the best available evidence for the efficacy and safety of the BS and NBT in BL. The results from this review may be of great value for the management of BLs, and designing the future studies

For future studies, we encourage implementation of protocols that include the patient characteristics, procedure details and outcomes in post-transplant BLs. These protocols should include detailed information about surgery performed (DDLT vs. LDLT, type of biliary reconstruction, use of splinting stents or T-tubes, catheter size for NBT, need for ductoplasty, intra-operative complications and hepatic artery injury); degree of BL (low-grade or high-grade); site of BL (anastomotic, T-tube or cut-surface); details of the endoscopic procedure (size endoprosthesis, duration of follow-up, complications) and salvage therapy if initial endoscopic treatment fails. It will be difficult to conduct a prospective randomized controlled trial comparing the efficacy of NBT to BS, as BS has largely replaced the NBT to become a standard treatment for post-transplant BLs in the last decade.

In conclusion, we report that both BS and NBTs are effective for treating post-transplant BL. Further, we note that the efficacy is greater for leaks not associated with the anastomosis. Both BS and NBT can be considered as an initial strategy for post OLT leaks, with serial cholangiography determining subsequent treatment approaches for persistent leaks. While CSEMS appear to be an emerging treatment option, the lack of comparative trials demonstrating clear efficacy is needed prior to widespread use.

\section{Conflicts of Interest}

The authors have no financial conflicts of interest.

\section{REFERENCES}

1. Global Observatory on Donation and Transplantation. Spanish National Transplant Organization (ONT) in collaboration with World healt Organization (WHO) [Internet]. Spain: GODT; [cited 2016 Oct]. Available from: http://www.transplant-observatory.org/summary.

2. Thuluvath PJ, Atassi T, Lee J. An endoscopic approach to biliary complications following orthotopic liver transplantation. Liver Int 2003;23:156162.

3. Akamatsu N, Sugawara Y, Hashimoto D. Biliary reconstruction, its complications and management of biliary complications after adult liver transplantation: a systematic review of the incidence, risk factors and outcome. Transpl Int 2011;24:379-392.

4. Sherman S, Shaked A, Cryer HM, Goldstein LI, Busuttil RW. Endoscopic management of biliary fistulas complicating liver transplantation and other hepatobiliary operations. Ann Surg 1993;218:167-175.

5. Ostroff JW. Management of biliary complications in the liver transplant patient. Gastroenterol Hepatol (N Y) 2010;6:264-272.

6. Arain MA, Attam R, Freeman ML. Advances in endoscopic management of biliary tract complications after liver transplantation. Liver 
Transpl 2013;19:482-498.

7. Delgado M, de Dios JF, Miño G, de la Mata M, Varo E. Role of endoscopic retrograde cholangiopancreatography in liver transplantation. Rev Esp Enferm Dig 1993;84:319-325.

8. Khuroo MS, Al Ashgar H, Khuroo NS, et al. Biliary disease after liver transplantation: the experience of the King Faisal Specialist Hospital and Research Center, Riyadh. J Gastroenterol Hepatol 2005;20:217-228.

9. Lee CS, Liu NJ, Lee CF, et al. Endoscopic management of biliary complications after adult right-lobe living donor liver transplantation without initial biliary decompression. Transplant Proc 2008;40:2542-2545.

10. Morelli J, Mulcahy HE, Willner IR, et al. Endoscopic treatment of post-liver transplantation biliary leaks with stent placement across the leak site. Gastrointest Endosc 2001;54:471-475.

11. Johnston TD, Reddy KS, Khan TT, Ranjan D. ERCP in the management of early versus late biliary leaks after liver transplantation. Int Surg 2006;91:301-305.

12. Park JS, Kim MH, Lee SK, et al. Efficacy of endoscopic and percutaneous treatments for biliary complications after cadaveric and living donor liver transplantation. Gastrointest Endosc 2003;57:78-85.

13. Pacholczyk M, Lagiewska B, Gontarczyk GW, et al. Biliary complications following liver transplantation: single-center experience. Transplant Proc 2006;38:247-249.

14. Liao JZ, Zhao Q, Qin H, et al. Endoscopic diagnosis and treatment of biliary leak in patients following liver transplantation: a prospective clinical study. Hepatobiliary Pancreat Dis Int 2007;6:29-33.

15. Sendino O, Fernández-Simon A, Law R, et al. Endoscopic management of bile leaks after liver transplantation: an analysis of two high-volume transplant centers. United European Gastroenterol J 2018;6:89-96.

16. Tung BY, Kowdley KV, Kimmey MB. Pancreatic fistula without pancreatitis after endoscopic biliary stent placement for bile leak after orthotopic liver transplantation. Gastrointest Endosc 1999;49:647-651.

17. Solmi L, Cariani G, Leo P, Miracolo A, Nigro G, Roda E. Results of endoscopic retrograde cholangiopancreatography in the treatment of biliary tract complications after orthotopic liver transplantation: our experience. Hepatogastroenterology 2007;54:1004-1008.

18. Leiting J, Arain M, Freeman ML, et al. Impact of early biliary complications on long-term outcomes in adult-to-adult living donor liver transplant recipients. Minerva Chir 2016;71:15-24.

19. Phillips MS, Bonatti H, Sauer BG, et al. Elevated stricture rate following the use of fully covered self-expandable metal biliary stents for biliary leaks following liver transplantation. Endoscopy 2011;43:512-517.

20. Chok KS, Chan AC, Sharr WW, et al. Outcomes of endo-radiological approach to management of bile leakage after right lobe living donor liver transplantation. J Gastroenterol Hepatol 2016;31:190-193.

21. Papachristou GI, Abu-Elmagd KM, Bond G, et al. Pancreaticobiliary complications after composite visceral transplantation: incidence, risk, and management strategies. Gastrointest Endosc 2011;73:1165-1173.

22. Gunawansa N, McCall JL, Holden A, Plank L, Munn SR. Biliary complications following orthotopic liver transplantation: a 10-year audit. HPB (Oxford) 2011;13:391-399.

23. Pfau PR, Kochman ML, Lewis JD, et al. Endoscopic management of postoperative biliary complications in orthotopic liver transplantation. Gastrointest Endosc 2000;52:55-63.

24. Rerknimitr R, Sherman S, Fogel EL, et al. Biliary tract complications after orthotopic liver transplantation with choledochocholedochostomy anastomosis: endoscopic findings and results of therapy. Gastrointest Endosc 2002;55:224-231.

25. Saab S, Martin P, Soliman GY, et al. Endoscopic management of biliary leaks after T-tube removal in liver transplant recipients: nasobiliary drainage versus biliary stenting. Liver Transpl 2000;6:627-632.

26. Sanna C, Giordanino C, Giono I, et al. Safety and efficacy of endoscopic retrograde cholangiopancreatography in patients with post-liver transplant biliary complications: results of a cohort study with long-term follow-up. Gut Liver 2011;5:328-334.

27. Tarantino I, Barresi L, Petridis I, Volpes R, Traina M, Gridelli B. Endoscopic treatment of biliary complications after liver transplantation. World J Gastroenterol 2008;14:4185-4189.

28. Traina M, Tarantino I, Barresi L, et al. Efficacy and safety of fully covered self-expandable metallic stents in biliary complications after liver transplantation: a preliminary study. Liver Transpl 2009;15:1493-1498.

29. DaVee T, Geevarghese SK, Slaughter JC, Yachimski PS. Refractory anastomotic bile leaks after orthotopic liver transplantation are associated with hepatic artery disease. Gastrointest Endosc 2017;85:984-992.

30. Martins FP, Phillips M, Gaidhane MR, Schmitt T, Kahaleh M. Biliary leak in post-liver-transplant patients: is there any place for metal stent? HPB Surg 2012;2012:684172.

31. Tsujino T, Isayama H, Sugawara $\mathrm{Y}$, et al. Endoscopic management of biliary complications after adult living donor liver transplantation. Am J Gastroenterol 2006;101:2230-2236.

32. Oh DW, Lee SK, Song TJ, et al. Endoscopic management of bile leakage after liver transplantation. Gut Liver 2015;9:417-423.

33. Shah SR, Dooley J, Agarwal R, et al. Routine endoscopic retrograde cholangiography in the detection of early biliary complications after liver transplantation. Liver Transpl 2002;8:491-494.

34. Osorio RW, Freise CE, Stock PG, et al. Nonoperative management of biliary leaks after orthotopic liver transplantation. Transplantation 1993;55:1074-1077.

35. Sherman S, Jamidar P, Shaked A, Kendall BJ, Goldstein LI, Busuttil RW. Biliary tract complications after orthotopic liver transplantation. Endoscopic approach to diagnosis and therapy. Transplantation 1995;60:467470.

36. Macfarlane B, Davidson B, Dooley JS, et al. Endoscopic retrograde cholangiography in the diagnosis and endoscopic management of biliary complications after liver transplantation. Eur J Gastroenterol Hepatol 1996;8:1003-1006.

37. Hwang S, Lee SG, Sung KB, et al. Long-term incidence, risk factors, and management of biliary complications after adult living donor liver transplantation. Liver Transpl 2006;12:831-838.

38. Ostroff JW, Roberts JP, Gordon RL, Ring EJ, Ascher NL. The management of T tube leaks in orthotopic liver transplant recipients with endoscopically placed nasobiliary catheters. Transplantation 1990;49:922-924.

39. Bourgeois N, Deviére J, Yeaton P, et al. Diagnostic and therapeutic endoscopic retrograde cholangiography after liver transplantation. Gastrointest Endosc 1995;42:527-534.

40. Lee DW, Jo HH, Abdullah J, Kahaleh M. Endoscopic management of anastomotic strictures after liver transplantation. Clin Endosc 2016;49:457-461. 